\title{
Distinct Subtypes of Metabotropic Glutamate Receptors Mediate Differential Actions on Excitability of Spinal Respiratory Motoneurons
}

\author{
Xiao-Wei Dong and Jack L. Feldman \\ Systems Neurobiology Laboratory, Departments of Neurobiology and Physiological Science, University of California, Los \\ Angeles, Los Angeles, California 90095-1763
}

\begin{abstract}
Metabotropic glutamate receptors (mGluRs) modulate neuronal function by affecting excitability and altering synaptic transmission. We have shown that the mGluR agonist (1S,3R)-1-amino1,3-cyclopentanedicarboxylic acid (1S,3R-ACPD) has multiple actions on phrenic motoneurons (PMNs), including reduction of inspiratory-modulated synaptic currents and an increase of neuronal excitability. We hypothesized that these actions were mediated by different mGluR subtypes. We have now identified the involvement of mGluR subtypes and their roles in modulating the excitability of PMNs and the consequent inspiratory motor output in an in vitro neonatal rat brainstem-spinal cord preparation. Activation of postsynaptic group-I mGluRs increases PMN excitability, associated with the production of an inward current and a decrease in membrane conductance, whereas activation of group-II or group-III mGluRs decreases PMN inspiratory-modulated synaptic current, probably via a presynaptic mechanism. To confirm further the distinction and the involvement of group-I and group-II/-III receptor subtypes affecting PMN excitability, we used the membrane permeable
\end{abstract}

cAMP analog 8-bromo-cAMP (8-Br-cAMP) to elevate intracellular CAMP concentration to mask or occlude any effects mediated via the cAMP cascade. 8-Br-cAMP attenuated the reduction of the inspiratory-modulated activity of PMNs by both (S)-4-carboxy-3-hydroxyphenylglycine (4C3HPG) and L-(+)-2amino-4-phosphonobutyric acid (L-AP4), agonists for group-II and group-III mGluRs, respectively, but did not affect the actions of 3,5-dihydroxyphenylglycine (DHPG), an agonist for group-I mGluRs. These three groups of mGluRs are all endogenously activated during the inspiratory phase. We conclude that three groups of mGluRs are functionally expressed in the phrenic nucleus and that their activation modulates PMN excitability via distinct mechanisms, with group-I acting at postsynaptic sites and group-II and group-III acting at presynaptic sites.

Key words: metabotropic glutamate receptors; group-I subtype; group-II; group-III; synaptic transmission; presynaptic; postsynaptic; excitability; potassium channels; brainstem; spinal cord; phrenic motoneurons; respiration
Metabotropic glutamate receptors (mGluRs) modulate neuronal function via affecting excitability and altering synaptic transmission (Schoepp and Conn, 1993; Gallagher et al., 1994; Pin and Duvoisin, 1995). The diversity of mGluR actions can be primarily attributed to different receptor subtypes [mGluR1-8 (Pin and Bockaert, 1995)] and their cellular localizations. Group-I mGluRs (mGluR1 and mGluR5) are coupled to phospholipase C and increase the synthesis of inositol 1,4,5-trisphosphate (Masu et al., 1991; Abe et al., 1992; Aramori and Nakanishi, 1992); they can be selectively activated by 3,5-dihydroxyphenylglycine (DHPG) (Schoepp et al., 1994). Group-I mGluRs appear to be localized postsynaptically (Martin et al., 1992; Baude et al., 1993; Lujan et al., 1996; Shigemoto et al., 1997) where they act to increase neuronal excitability (Davies et al., 1995; Netzeband et al., 1997; Schoppa and Westbrook, 1997; Schrader and Tasker, 1997). Group-II (mGluR2 and mGluR3) and group-III (mGluR4 and mGluR6-8) mGluRs are negatively coupled to adenylyl cyclase and inhibit the formation of cAMP (Tanabe et al., 1992, 1993;

\footnotetext{
Received Nov. 5, 1998; revised April 2, 1999; accepted April 12, 1999.

This work was supported by the National Institutes of Health Grant NS24742. We thank Dr. Didier Morin for participating in the early experimental studies.

Correspondence should be addressed to Dr. Jack L. Feldman, Department of Neurobiology, University of California, Los Angeles, Box 951763, Los Angeles, CA 90095-1763.

Dr. Dong's present address: Schering-Plough Research Institute, 2015 Galloping Hill Road, Kenilworth, NJ 07033.

Copyright (C) 1999 Society for Neuroscience $\quad 0270-6474 / 99 / 195173-12 \$ 05.00 / 0$
}

Nakajima et al., 1993; Okamoto et al., 1994; Saugstad et al., 1994; Duvoisin et al., 1995). Group-II and group-III receptors are predominantly localized in presynaptic terminals (Shigemoto et al., 1995, 1996, 1997) where they inhibit transmitter release (Forsythe and Clements, 1990; Baskys and Malenka, 1991; Trombley and Westbrook, 1992; Gereau and Conn, 1995; Salt and Eaton, 1995; Vignes et al., 1995; Macek et al., 1996; Schrader and Tasker, 1997).

The physiological roles of mGluR subtypes in identified neurons with measurable behaviors warrant investigation. Although the effects of different mGluRs in single neurons have been extensively reported (Poncer et al., 1995; Salt and Eaton, 1995; Macek et al., 1996; Libri et al., 1997; Schoppa and Westbrook, 1997; Schrader and Tasker, 1997), their roles in regulating integrative functions or in behavior are poorly understood. In this study, we examine the actions of different mGluRs affecting respiratory motor output, in particular, on phrenic motoneurons (PMNs) that receive inspiratory drive from the brainstem and control the diaphragm, the principal inspiratory muscle. We performed this study in an in vitro brainstem-spinal cord preparation, in which the transmission of endogenous inspiratory drive to PMNs is mediated by glutamate acting primarily at non-NMDA receptors (McCrimmon et al., 1989; Liu et al., 1990; Feldman and Smith, 1994). Thus, we can study mGluR actions at an identified, endogenously driven glutamatergic synapse onto a functionally identified neuron participating in a meaningful and measurable 
A A $\quad$ DHPG $(200 \mu \mathrm{M}$, local $)$

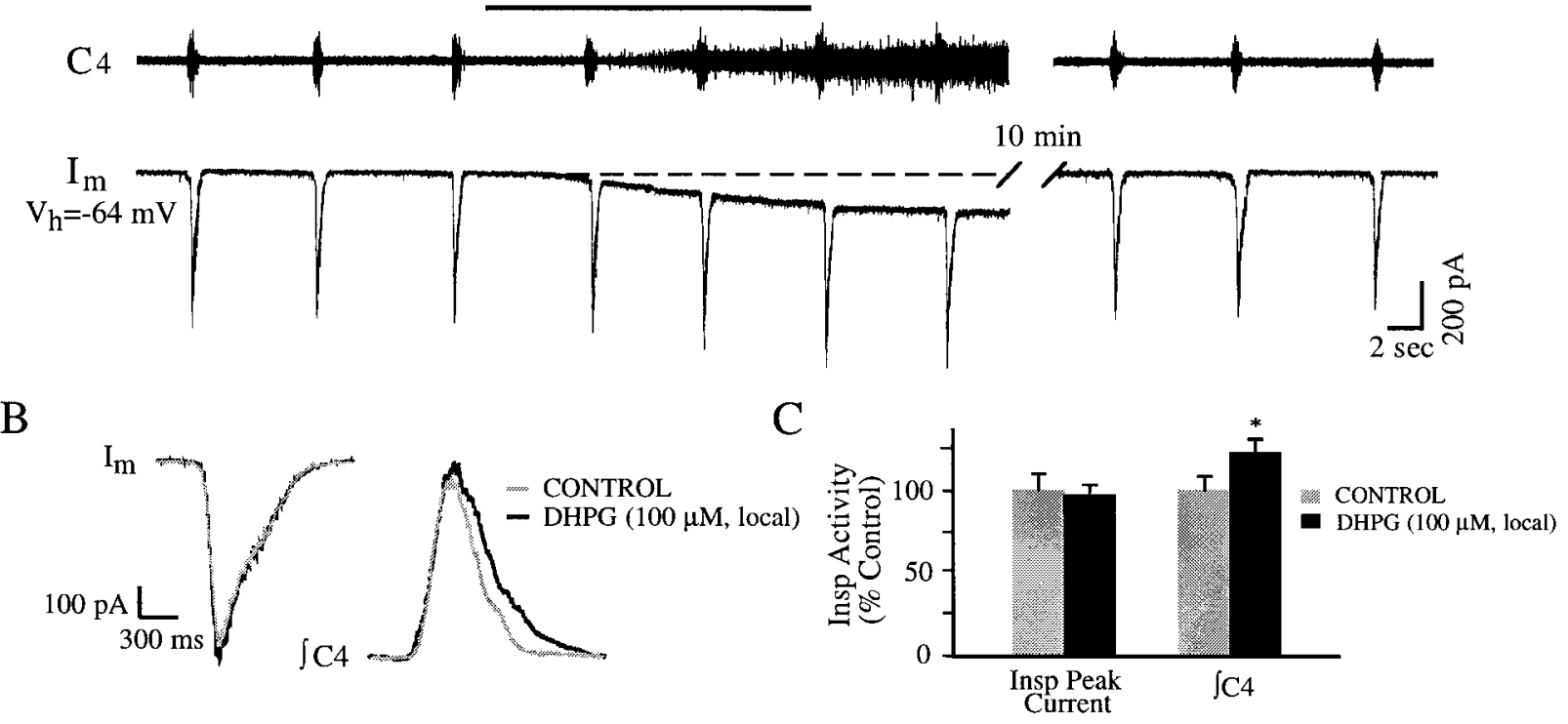

$\operatorname{TTX}(1 \mu \mathrm{M}$, bath $)$

D CNQX (100 $\mu \mathrm{M}$, bath)

MK-801 $(250 \mu \mathrm{M}$, bath $) \quad$ +DHPG $(200 \mu \mathrm{M}$, local $)$

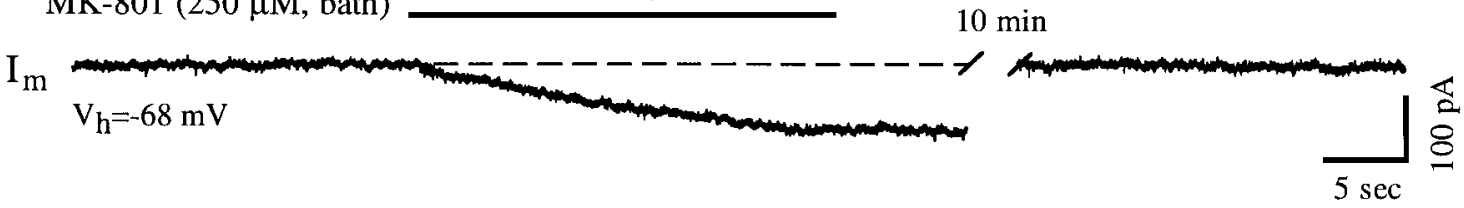

Figure 1. Effects of the group-I mGluR agonist DHPG on membrane currents of a PMN and the activity in C4 ventral roots. $A$, Raw traces of simultaneously recorded $\mathrm{C} 4$ ventral root activity $(\mathrm{C} 4$; top $)$ and membrane current $\left(I_{m} ;\right.$ bottom $)$ of a PMN showing responses to locally applied DHPG $(200 \mu \mathrm{M}$; period of DHPG application indicated by the horizontal line). At this concentration, DHPG caused tonic activity in C4 roots. Concurrently, DHPG induced an inward current in the PMN, which was voltage-clamped at the end-expiratory potential $\left(\mathrm{V}_{h}\right)$ of $-64 \mathrm{mV}$. Note that the inspiratory drive current was not significantly affected. $B$, Superimposed inspiratory drive currents $\left(I_{m}\right)$ and integrated $C 4$ root activity $\left(\int C 4\right)$ before and during the treatment with a lower concentration (100 $\mu \mathrm{M}$, local) of DHPG. Inspiratory drive currents were not significantly affected by DHPG. The inspiratory discharges of $\mathrm{C} 4$ roots were increased. Traces are averages from six consecutive inspiratory phases in control conditions and during the period of peak effect on C4 activity after drug application. $C$, Summary of effects of DHPG (100 $\mu \mathrm{M}$, local) on peak inspiratory drive currents and C4 discharges. Vertical bars are averages from six successive inspiratory phases of peak inspiratory drive currents (left) and integrated inspiratory discharges of C4 (JC4; right) during peak effect of the drug pooled from eight and six preparations, respectively. Error bars indicate SEM. An asterisk indicates a significant difference $(p<0.05 ; t$ test) from control values. Insp, Inspiratory. D, Raw trace showing the persistence of DHPG-induced inward current in a PMN after the bath application of a cocktail containing TTX $(1 \mu \mathrm{M})$ and ionotropic glutamate receptor antagonists CNQX (100 $\mu \mathrm{M})$ and MK-801 (250 $\mu \mathrm{M})$.

behavior. A broad spectrum mGluR agonist (1S,3R)-1-amino-1,3cyclopentanedicarboxylic acid ( $1 S, 3 R$-ACPD) reduces inspiratorymodulated synaptic currents and increases the excitability of PMNs (Dong et al., 1996). These actions are mediated by distinct mechanisms at pre- and postsynaptic sites. We have now identified the mGluR subtypes underlying these effects by examining the actions of specific agonists on endogenous inspiratorymodulated synaptic current, baseline membrane current, and action potential patterns in PMNs. We then examined the effects of perturbing second messenger pathways associated with group-I and group-II/-III receptor subtypes. We analyzed the effects of these various perturbations on postsynaptic membrane properties of PMNs and on the frequency and amplitude of miniature EPSCs (mEPSCs).

Parts of this paper have been published previously (Dong and Feldman, 1995b, 1996).

\section{MATERIALS AND METHODS}

En bloc preparation. Experiments were performed on in vitro preparations of brainstem and spinal cord from 0 - to 4-d-old neonatal rats.
Details of the preparation have been described elsewhere (Smith and Feldman, 1987; Liu et al., 1990; Dong and Feldman, 1995a). In brief, the brainstem and cervical spinal cord were isolated from 0- to 4-d-old Sprague Dawley rats anesthetized with ether or hypothermia. The en bloc neuraxis was then pinned down with the ventral surface upward on Sylgard resin in a recording chamber and continuously superfused with normal artificial CSF (aCSF) (in mM): $128 \mathrm{NaCl}, 3 \mathrm{KCl}, 1.5 \mathrm{CaCl}_{2}, 1$ $\mathrm{MgSO}_{4}, 21 \mathrm{NaHCO}_{3}, 0.5 \mathrm{NaH}_{2} \mathrm{PO}_{4}$, and $30 \mathrm{D}$-glucose, equilibrated with $95 \% \quad \mathrm{O}_{2} / 5 \% \quad \mathrm{CO}_{2}$. The bath temperature was gradually raised from $10-15^{\circ} \mathrm{C}$ (for isolation) to $25-26^{\circ} \mathrm{C}$ before recording.

Electrophysiology. Respiratory activity was recorded with suction electrodes from the $\mathrm{C} 4$ ventral root, which contains phrenic motoneuronal axons, and sometimes simultaneously from cranial nerves (X and XII). Signals were amplified (Grass P511K; Grass Instrument, Quincy, MA), rectified, and low-pass filtered (Paynter filter; $\tau=15 \mathrm{msec}$ ).

Electrodes for whole-cell patch-clamp recordings were pulled from aluminosilicate glass (A-M Systems, Everett, WA) with a tip size of $\sim 2$ $\mu \mathrm{m}$ and a resistance of 3.5-5 $\mathrm{M} \Omega$ when filled with solution containing (in $\mathrm{mM}$ ): $120 \mathrm{~K}^{+}$-gluconate, $1 \mathrm{CaCl}_{2}, 5 \mathrm{NaCl}, 10 \mathrm{HEPES}, 2 \mathrm{ATP}$ (magnesium salt), and 10 1,2-bis-(2-aminophenoxy)ethane- $N, N, N^{\prime}, N^{\prime}$-tetraacetic acid (tetrapotassium salt), at pH 7.3 adjusted by KOH. Successful whole-cell recording was ensured by the initial formation of a gigaohm seal $(2-10 \mathrm{G} \Omega)$ and low series resistance $\left(R_{S} ; 8-15 \mathrm{M} \Omega\right) . R_{S}$ was esti- 


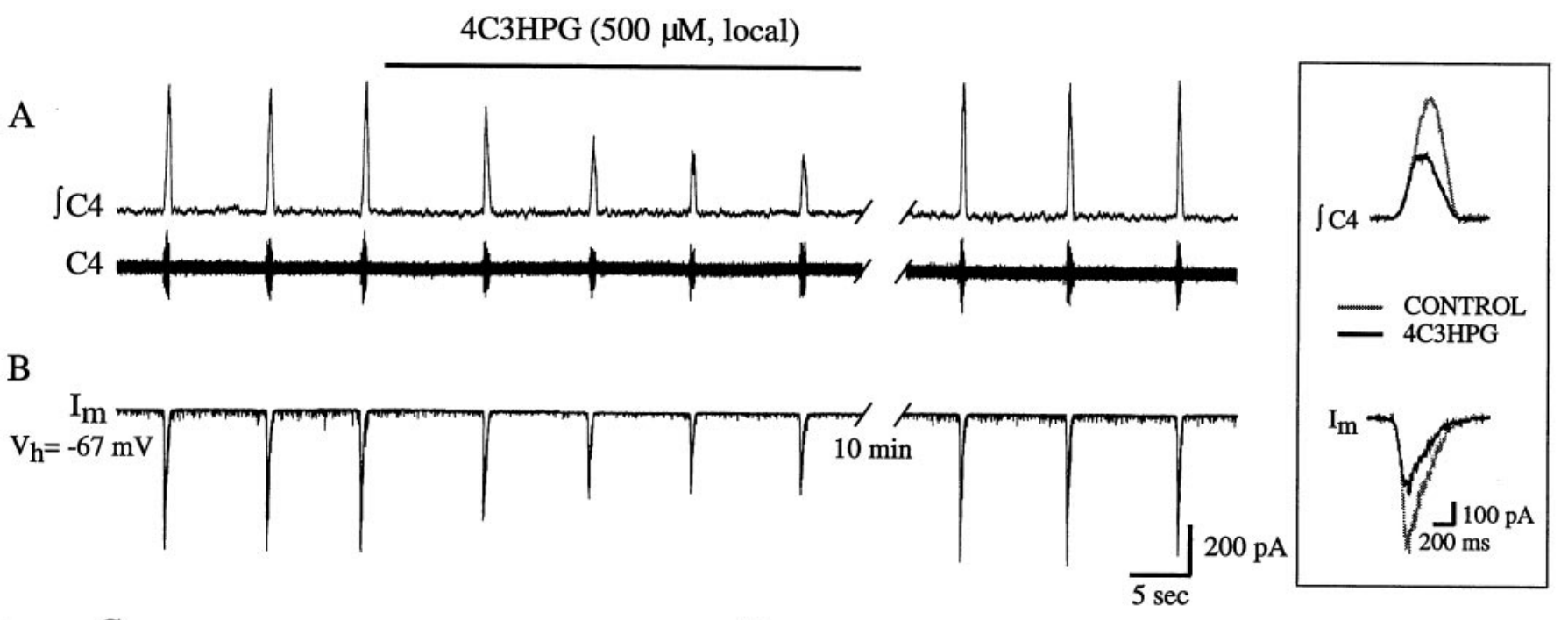

$\mathrm{C}$

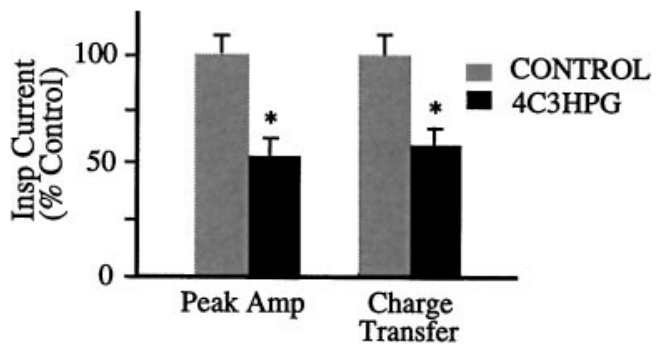

$\mathrm{D}$

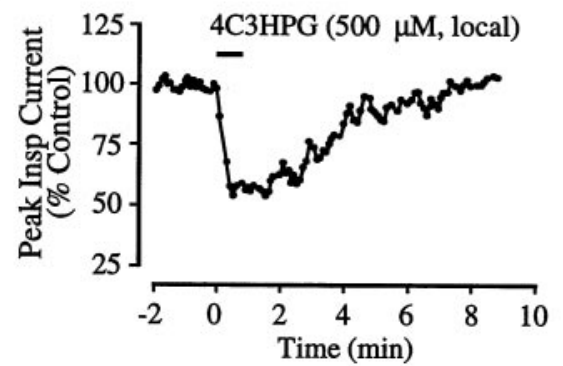

Figure 2. Activation of group-II mGluRs depresses synaptic transmission to and output from PMNs. $A, B$, Local application of the agonist 4 C3HPG $(500 \mu \mathrm{M})$ simultaneously decreased the activity of $\mathrm{C} 4$ ventral roots $(A)$ and the inspiratory drive current of a PMN that was voltage-clamped at the end-expiratory potential of $-60 \mathrm{mV}(B)$. Inset, The superimposed traces are averages of six consecutive inspiratory drive currents of a PMN $\left(I_{m}\right)$ and integrated inspiratory discharges of $\mathrm{C} 4$ roots $\left(\int \mathrm{C} 4\right)$ in control conditions and during the period of peak effect after drug application. $C$, Summary of effects of 4C3HPG $(500 \mu \mathrm{M}$, local) on peak amplitude $(A m p)$ and charge transfer of inspiratory drive currents is shown. Vertical bars are averages of six successive inspiratory drive currents during peak effect of the drug pooled from seven preparations. Error bars indicate SEM. An asterisk indicates a significant difference $(p<0.05 ; t$ test) from control values. $D$, Time course of peak inspiratory drive currents in response to $4 \mathrm{C} 3 \mathrm{HPG}$ (500 $\mu \mathrm{M}$, local) is shown. Each data point is the average of three consecutive peak inspiratory drive currents expressed as the percentage of the control value.

mated using $100 \mathrm{~Hz},-10 \mathrm{mV}, 5 \mathrm{msec}$ voltage pulses. When in voltageclamp mode, a $60-80 \% R_{S}$ compensation was used. During experiments, $R_{S}$ was frequently checked, and data were discarded if large increases occurred during the course of the recording. PMNs were voltageclamped at the end-expiratory potentials of -60 to $-75 \mathrm{mV}$. Data obtained from PMNs displaying fast $\mathrm{Na}^{+}$currents during inspiration (indicative of poor space clamp) were not included in the analysis. Signals were amplified with a patch-clamp amplifier (AXOPATCH 1D or AXOPATCH 200; Axon Instruments, Foster City, CA) and filtered at $2-5 \mathrm{kHz}$ (Bessel filter).

Current-voltage $(I-V)$ relations were obtained by applying a series of command voltage step pulses (step size, 2-5 mV; width, 100-200 msec; frequency, $2 \mathrm{~Hz}$ ) controlled by software (Axodata or Axoscope; Axon Instruments). $I-V$ curves were obtained by plotting current change (averaged steady-state current values at 5-10 msec before offset of voltage step) against membrane potential. Because most PMNs did not exhibit slow time-dependent membrane properties over the testing voltage range and the membrane current reached steady state at $50 \mathrm{msec}$ after the onset of a voltage pulse (Dong et al., 1996), steady-state current could be obtained using voltage pulses with widths $\geq 100 \mathrm{msec}$. Membrane potentials $\left(\mathrm{V}_{m}\right)$ were adjusted for liquid junction potentials $(-10 \mathrm{mV})$. Neuron input conductance $\left(G_{N}\right)$ was calculated at the holding potential $(-60$ to $-75 \mathrm{mV}$ ) from the slope of a least-squares regression line fitted to the data.

Neurons subjected to experimental measurements and data analysis satisfied various criteria described previously (Liu et al., 1990; Lindsay and Feldman, 1993). Briefly, these neurons had resting membrane potentials of at least $-60 \mathrm{mV}$ and displayed rhythmic synaptic drive currents in synchrony with the inspiratory burst activity on the $\mathrm{C} 4$ ventral root. These neurons were located at intermediate laterality and 130-300 $\mu \mathrm{m}$ below the ventral surface at the $\mathrm{C} 4$ segment, consistent with the location of the PMN pool in neonatal rats (Lindsay et al., 1991). Axons of these neurons were contained in the $\mathrm{C} 4$ ventral root, indicated by antidromic activation by stimulating the $\mathrm{C} 4$ nerve through the suction electrode. Moreover, their other intrinsic properties, such as input resistance, were consistent with the measurements made in neurons identified as PMNs (Smith et al., 1988).

Pharmacological substances and application. The drugs used included $(R S)$-DHPG (Tocris Cookson, Ballwin, MO; 30-200 $\mu \mathrm{M}),(S)$-4-carboxy3-hydroxyphenylglycine (4C3HPG; Tocris Cookson; 30-500 $\mu \mathrm{M})$, L-(+)2-amino-4-phosphonobutyric acid (L-AP4; Tocris Cookson; 3-50 $\mu \mathrm{M}$ ), $(R S)$-1-aminoindan-1,5-dicarboxylic acid (AIDCA; Tocris Cookson; 2 $\mathrm{mM}),(2 S)-\alpha$-ethylglutamic acid (EGLU; Tocris Cookson; $2 \mathrm{mM}),(R S)$ $\alpha$-methylserine- $O$-phosphate (MSOP; Tocris Cookson; 1-2 mM), 8-bromo-cAMP (8-Br-cAMP; Research Biochemicals, Natick, MA; 0.8$1.2 \mathrm{mM}$ ), 6-cyano-7-nitroquinoxaline-2,3-dione (CNQX; Tocris Cookson; $100 \mu \mathrm{M}),(+)-5$-methyl-10,11-dihydro-5H-dibenzo [a,d] cyclohepten-5,10iminemaleate (MK-801; Research Biochemicals; $250 \mu \mathrm{M}$ ), and tetrodotoxin (TTX; Sigma, St. Louis, MO; $1 \mu \mathrm{M}$ ).

Experiments were performed while preparations were perfused with normal aCSF solution as described above. Drugs were added to the spinal cord bath and/or applied locally via a glass pipette placed over the midcervical spinal cord region containing the PMN pool. Bath application was used to determine the minimum concentrations required for drug action. With bath application of drugs, the chamber was partitioned into two compartments at the level of the spinomedullary junction by a transverse barrier of petroleum jelly (Vaseline) across the neuraxis (Liu et al., 1990). This allows selective drug application to the spinal cord to 


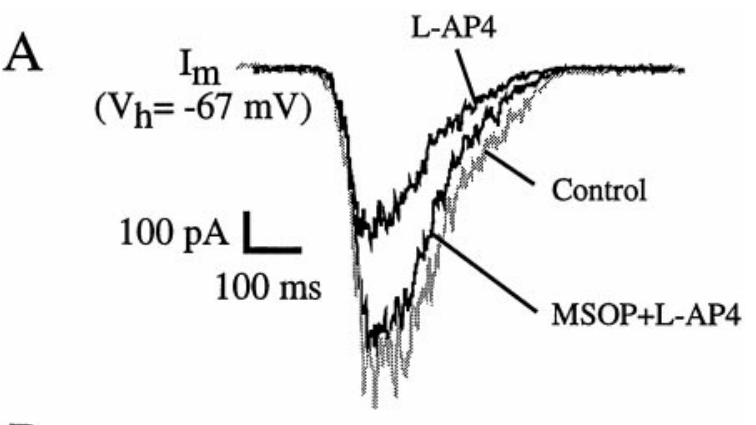

B

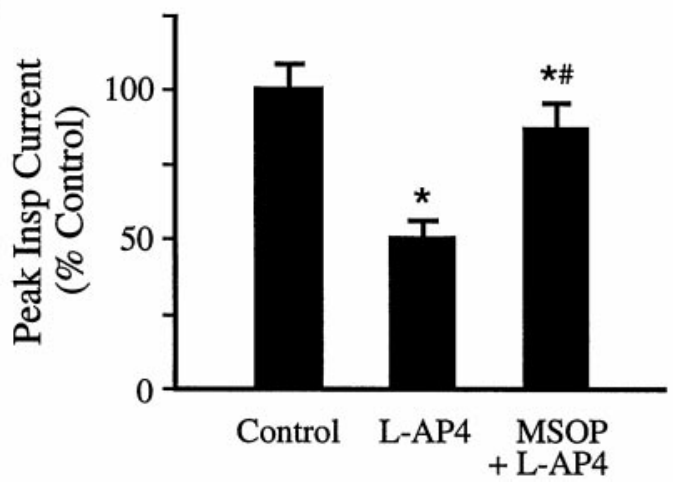

Figure 3. Activation of group-III mGluRs reduces PMN inspiratory drive currents. $A$, Locally applied L-AP4 $(50 \mu \mathrm{M})$ potently reduced inspiratory drive currents. This effect was effectively blocked by the antagonist MSOP. Local application of MSOP (1 mM) began 5 min before L-AP4 $(50 \mu \mathrm{M}$, local) application and continued during the course of the L-AP4 test. Traces are the averages of six consecutive inspiratory drive currents in each condition. $B$, Summary of the L-AP4 (50 $\mu \mathrm{M}$, local) effect on peak inspiratory drive currents with and without concurrent application of MSOP (1 mM, local) is shown. Error bars indicate SEM. An asterisk indicates a significant difference ( $p<0.05 ; t$ test) from control values. A pound symbol indicates a significant difference $(p<0.05 ; t$ test $)$ from values obtained from the L-AP4 condition.

affect synaptic transmission at the spinal level without disturbing processes at the brainstem level, where the descending inspiratory motor drive originates. Drugs were added to the spinal compartment at concentrations starting from the minimum necessary to induce a clear change in $\mathrm{C} 4$ root activity, and 6-8 $\mathrm{min}$ was allowed for equilibrium.

Vaseline often caused difficulty in obtaining good seals for patch recording. Thus, when such recordings were desired, test agents were applied locally in an unpartitioned chamber via pressure ejection from single- or multibarrel pipettes positioned close to the ventral surface of the midcervical spinal cord over the PMN pool (Liu et al., 1990). Each barrel had an orifice of $8-10 \mu \mathrm{m}$ and was filled with a drug solution, saline, or aCSF. Application of drugs was controlled by brief air pressure pulses to the appropriate drug barrel. Control injections were made by ejecting saline or aCSF. The observed change caused by a test drug acting at a spinal site rather than at a supraspinal site was indicated by unchanged respiratory rate recorded from the $\mathrm{C} 4$ root and unchanged amplitude recorded from cranial nerves (X and XII).

In experiments examining the effect of changing intracellular cAMP concentration on drug action with $\mathrm{C} 4$ root recording, bath application of 8-Br-cAMP was combined with local application of an agonist. Thus, after the effect of a locally applied agonist was examined, 8-Br-cAMP was added to the spinal compartment, and then the agonist was tested again. The application of 8 -Br-cAMP began at least $8-10$ min before agonist application and continued during the agonist test.

Data acquisition and analysis. Data were recorded on videotape via pulse code modulation (Vetter model 3000; A. R. Vetter, Rebersburg, PA; sampled at $10-40 \mathrm{kHz}$ per channel) for off-line analysis. Selected segments of records were digitized at $5-25 \mathrm{kHz}$ using an analog-to-digital converter and were stored on a Vaxstation 3200 computer disk (Digital Equipment Corporation, Maynard, MA) or on a Pentium computer disk for subsequent computer-aided analysis.
For analysis of changes of respiratory drive, the average values of peak amplitude and area of inspiratory-modulated synaptic current (charge transfer) or integrated $\mathrm{C} 4$ ventral root discharges were computed from respiratory cycles before and after drug application. Statistical values are reported as means \pm SEM. Differences between means were assessed by Student's $t$ test, and a value of $p<0.05$ was considered significant.

For analysis of perturbations of frequency and amplitude of mEPSCs, the data were first filtered using a Wiener (optimal) filter (Press et al., 1989; Barkat, 1991), which greatly attenuates background noise without significantly affecting the characteristics of the original signal (Liu and Feldman, 1992). Events were detected using a threshold detector. Then under visual inspection, events above noise level were collected for data analysis. The reliability of detection of unitary events was ensured by a high signal-to-noise ratio (>2.2) (Liu and Feldman, 1992); the amplitudes of mEPSCs were well above noise level in each cell tested. We did not observe any presumptive mEPSCs of size below $2.2 \times$ the mean noise level. We therefore assume that we detected almost all spontaneous EPSCs. To ensure identical voltage control before and after drug treatment so that the error in amplitude measurement because of inadequate space clamp would be similar under these two conditions, we monitored the series resistance and discarded data if significant increases occurred during the course of the recording. All collected EPSCs were then subject to analysis. For each condition, cumulative probability distribution histograms for interval and amplitude were constructed. Statistical significance for the difference between distributions was assessed by the Kolmogorov-Smirnov test (Van der Kloot, 1991), and a value of $p<0.05$ was considered significant.

\section{RESULTS}

Phrenic motoneurons receive rhythmic excitatory inspiratory inputs from bulbospinal inspiratory neurons. Under voltage-clamp conditions in the brainstem-spinal cord preparation, PMNs exhibit large, fast-rising, and slow-declining EPSCs during the inspiratory phase of the respiratory cycle (Fig. 1) (Liu et al., 1990; Dong et al., 1996). C4 ventral roots, which contain PMN axons, display spontaneous periodic bursts of discharges representing PMN population activity during the inspiratory phase (Fig. 1).

\section{Enhancement of excitability of PMNs by group-I mGluRs}

To determine the role of group-I mGluRs in affecting PMN excitability, we examined the effect of an agonist for group-I mGluRs, DHPG (Schoepp et al., 1994), on membrane currents of PMNs and on C4 ventral root activity. DHPG (50-200 $\mu \mathrm{M}$, local) produced an inward current $\left(I_{\mathrm{DHPG}} ; 50-200 \mathrm{pA}\right)$ in all PMNs examined $(n=8)$ when the membrane potentials were clamped at end-expiratory potentials ( -60 to $-75 \mathrm{mV}$; Fig. 1). The inspiratory-modulated synaptic currents, however, were not significantly affected (96 $\pm 6 \% ; n=8$; Fig. $1 A-C)$. Inspiratory discharges in $\mathrm{C} 4$ ventral roots increased at low concentrations of DHPG ( $\leq 150 \mu \mathrm{M}$, local; $n=12$; Fig. $1 B, C)$. At $100 \mu \mathrm{M}$ DHPG (local), the integrated $\mathrm{C} 4$ root discharge increased to $123 \pm 8 \%$ of control $(n=6$; Fig. $1 C)$. At high concentrations $(>150 \mu \mathrm{M}$, local $)$, DHPG induced tonic discharges in the $\mathrm{C} 4$ roots $(n=6$; Fig. $1 A)$. No changes in respiratory frequency (Fig. $1 A$ ) or in inspiratory activity of cranial nerves (X and XII) (data not shown) were observed after local application of DHPG to the midcervical spinal cord.

The current induced by DHPG could result from actions of DHPG in addition to its presumed effect on postsynaptic group-I mGluRs, including (1) increased activity of spinal interneurons projecting to PMNs and (2) actions mediated by ionotropic GluRs. To elucidate the mechanisms underlying $I_{\text {DHPG }}$, we examined the effects of DHPG after treatment with TTX $(1 \mu \mathrm{M})$ to block voltage-dependent $\mathrm{Na}^{+}$action potentials and associated synaptic transmission and with MK-801 (250 $\mu \mathrm{M})$ and CNQX $(100 \mu \mathrm{M})$, NMDA and non-NMDA receptor antagonists, respec- 
A

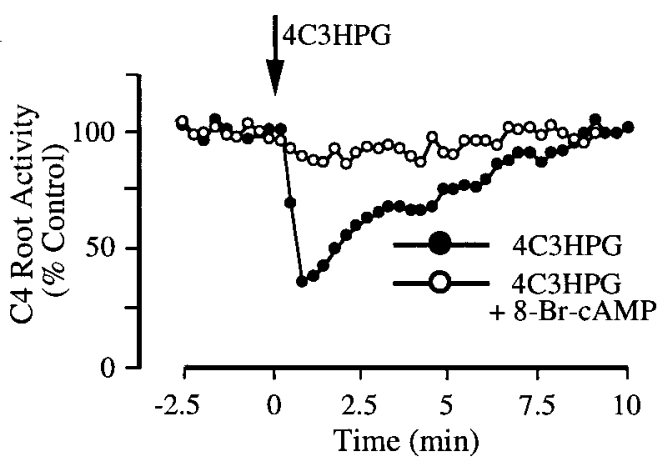

$\mathrm{C}$

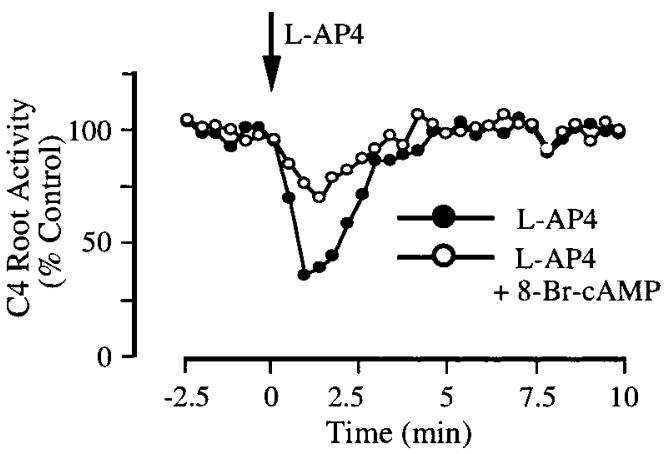

B

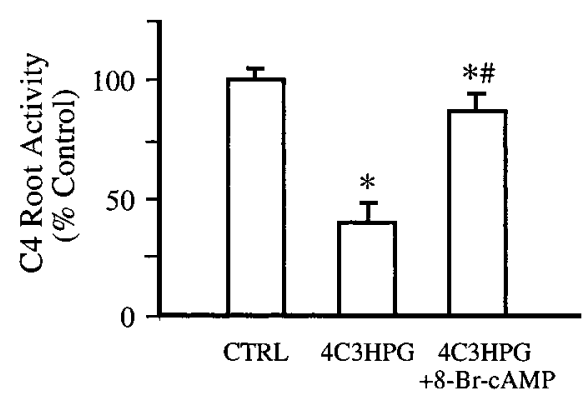

$\mathrm{D}$

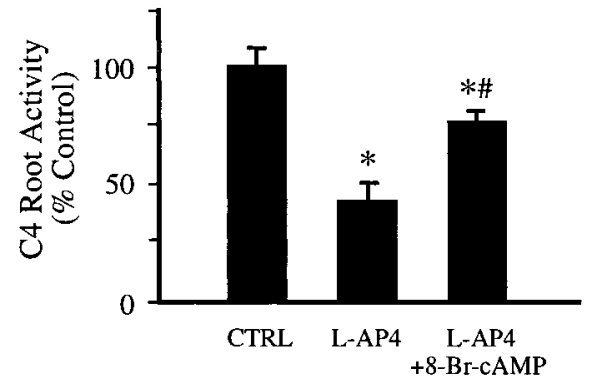

Figure 4. Elevation of intracellular cAMP attenuates the effects mediated by group-II and group-III mGluRs. $A, C$, Time courses of changes of C4 root inspiratory discharges in response to local application of 4C3HPG $(500 \mu \mathrm{M} ; A)$ and L-AP4 $(50 \mu \mathrm{M} ; C)$ with and without 8 -Br-cAMP $(1$ mM, bath) treatment. Effects of both $4 \mathrm{C} 3 \mathrm{HPG}$ and L-AP4 on inspiratory discharges were significantly attenuated by 8-Br-cAMP. Bath application of 8-Br-cAMP began 8 min before 4C3HPG or L-AP4 application and continued during the course of each agonist's application. Each data point is the average of three consecutive integrated inspiratory discharges expressed as the percentage of the control value. $B$, $D$, Pooled data from six preparations showing attenuated effects of 4C3HPG $(B)$ and L-AP4 $(D)$ on C4 root inspiratory activity by 8-Br-cAMP. Error bars indicate SEM. An asterisk indicates a significant difference $(p<0.05 ; t$ test) from control values. A pound symbol indicates a significant difference $(p<0.05 ; t$ test) from values obtained from the 4C3HPG or L-AP4 condition. CTRL, Control.

tively, to block currents mediated by ionotropic glutamate receptors. Under these conditions, DHPG continued to produce inward currents (six of six neurons; Fig. 1D), indicating a direct action on postsynaptic mGluRs of PMNs.

\section{Suppression of synaptic transmission to PMNs by group-II and group-III}

We showed previously (Dong et al., 1996) that simultaneous activation of different mGluR subtypes by $1 S, 3 R$-ACPD, a broadspectrum agonist, affected several currents in PMNs, including the induction of an inward current and the decrease of inspiratory drive current. Because the above results indicate that group-I mGluRs induce an inward current but do not affect inspiratory drive current, receptors in other groups were candidates for mediating the suppression of inspiratory drive current. We therefore examined the role of group-II mGluRs by testing the effect of an agonist, 4C3HPG (Birse et al., 1993; Kingston et al., 1995), on PMN membrane currents and C4 ventral root activity. 4C3HPG decreased inspiratory drive current and spontaneous EPSCs during the expiratory phase $(n=7)$, with no detectable effects on baseline membrane current (Fig. 2B). The reductions of peak and total charge transfer of inspiratory drive current by locally applied 4C3HPG $(500 \mu \mathrm{M})$ were $53 \pm 8$ and $58 \pm 7 \%$ of control $(n=7)$, respectively (Fig. $2 \mathrm{C}$ ). The effect of $4 \mathrm{C} 3 \mathrm{HPG}$ began within one respiratory cycle $(<10 \mathrm{sec})$ after drug application and reached peak within $1 \mathrm{~min}$. After washout, the inspiratory drive current returned to the control level within 5-8 min (Fig. 2D). Concurrent with the reduction of inspiratory drive current, a decrease in inspiratory discharges in $\mathrm{C} 4$ ventral roots occurred (Fig. $2 A$ ). The effect of
4C3HPG on $\mathrm{C} 4$ roots had a time course similar to that of the effect on inspiratory current of PMNs (Fig. $2 A$ ).

The role of group-III mGluRs was also examined. L-AP4, an agonist for group-III mGluRs (Bushell et al., 1995; Tones et al., 1995), inhibits synaptic transmission to PMNs (Liu et al., 1990). L-AP4 potently reduced the inspiratory current of PMNs (Fig. 3) without any effect on the baseline current. The peak inspiratory current was reduced to $51 \pm 6 \%(n=6)$ of control by $50 \mu \mathrm{M} \mathrm{L}-\mathrm{AP} 4$. Concurrent with the reduction of inspiratory current of PMNs, a decrease in inspiratory discharges in $\mathrm{C} 4$ ventral roots occurred in response to L-AP4 (data not shown). In the presence of MSOP (1 $\mathrm{mM}$, local), an antagonist for group-III mGluRs (Thomas et al., 1996), the effect of L-AP4 was diminished; $50 \mu \mathrm{M}$ L-AP4 reduced inspiratory current only to $88 \pm 7 \%(n=6$; Fig. 3$)$.

There were no changes in respiratory frequency with either 4C3HPG (Fig. 2) or AP-4 (data not shown) applied locally to the spinal cord.

\section{Effects of elevation of intracellular cAMP on mGluR-mediated actions}

The various mGluRs are coupled to different second messenger cascades (Masu et al., 1991; Abe et al., 1992; Aramori and Nakanishi, 1992). To confirm further the distinction of the effects on PMN excitability of group-I and group-II/-III receptor subtypes, we examined the involvement of specific second messenger pathways. The membrane-permeable cAMP analog 8-Br-cAMP was used to elevate intracellular cAMP concentration so that any effects mediated via the cAMP cascade would be masked or occluded. 


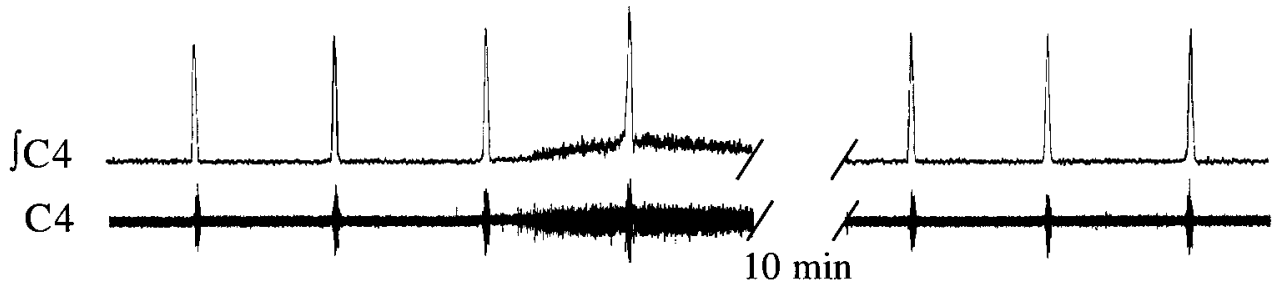

B

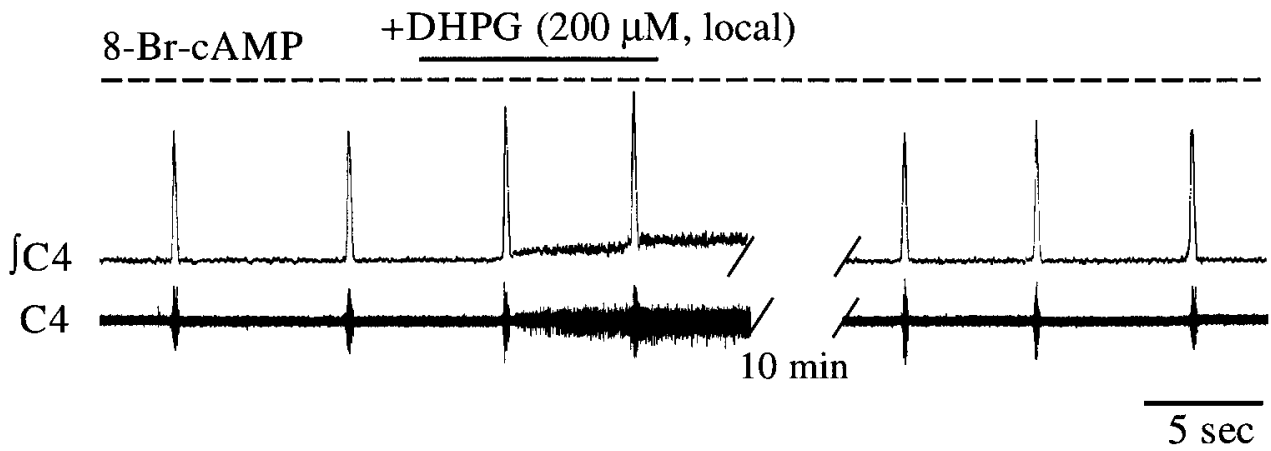

Figure 5. Lack of effect of intracellular cAMP elevation on the effect of group-I mGluR activation. $A$, Local application of DHPG (200 $\mu \mathrm{M})$ caused tonic discharges in $\mathrm{C} 4$ ventral roots. $B$, This effect was unaltered by treatment with 8-Br-cAMP. C4, Raw trace of $\mathrm{C} 4$ root activity is shown. $\int \mathrm{C} 4$, Integrated trace of $\mathrm{C} 4$ root activity is shown. Protocols described in Figure 4 were used for the 8-Br-cAMP treatment. The horizontal dashed line in $B$ indicates the period of 8 -Br-cAMP treatment.

In the presence of 8 -Br-cAMP $(0.8-1.2 \mathrm{mM})$ in the spinal bath of a partitioned chamber, the ability of both 4C3HPG and L-AP4 to reduce inspiratory-modulated activity in the $\mathrm{C} 4$ roots was greatly attenuated (Fig. 4). Thus, 4C3HPG (500 $\mu \mathrm{M})$ could only reduce $\mathrm{C} 4$ root discharges to $87 \pm 6 \%(n=6)$ of control, compared with $40 \pm 7 \%$ before 8 -Br-cAMP treatment (Fig. $4 A, B)$, and L-AP4 $(50 \mu \mathrm{M})$ could only reduce $\mathrm{C} 4$ root discharges to $77 \pm 7 \%(n=6)$ of control, compared with $42 \pm 9 \%$ before 8-Br-cAMP treatment (Fig. $4 C, D$ ). In contrast, the effect of DHPG was unaffected by 8 -Br-cAMP $(n=4)$, i.e., it continued to elicit tonic discharges in $\mathrm{C} 4$ ventral roots (Fig. 5).

\section{Differential effects of distinct mGluR subtypes on postsynaptic membrane properties}

To elucidate the ionic mechanisms underlying the effects on baseline membrane current and inspiratory drive current mediated by the various mGluR subtypes, we examined the PMN current-voltage $(I-V)$ relationship before and after drug treatment after synaptic isolation by TTX (1 $\mu \mathrm{M}$, bath; Fig. 6).

DHPG increased input resistance, as indicated by the reduced slope of the $I-V$ curve (Fig. $6 A$ ). The membrane input resistance at the resting potential $(-60$ to $-75 \mathrm{mV}$ ) increased to $159 \pm 8 \%$ of control $(n=6)$ after DHPG treatment (30 $\mu \mathrm{M}$, bath). The $I-V$ relationship for $I_{\mathrm{DHPG}}$ (Fig. $6 \mathrm{~B}$ ) was obtained by subtracting the $I-V$ relationship during DHPG treatment from that obtained under control conditions (Fig. $6 A$ ). $I_{\mathrm{DHPG}}$ decreased linearly with hyperpolarizing potentials (Fig. 6B). A reversal potential of $-102 \pm 6 \mathrm{mV}$ for $I_{\mathrm{DHPG}}$ was seen in four of six PMNs within the testing voltage range $(-50$ to $-120 \mathrm{mV})$.

To examine the possible postsynaptic actions of group-II and group-III mGluRs on PMNs, we also examined the effects of 4C3HPG $(n=5)$ and L-AP4 $(n=4)$. In contrast to the group-I agonist DHPG, neither 4C3HPG nor L-AP4 had a significant effect on the $I-V$ relationship over the test voltage range $(-50$ to $-120 \mathrm{mV}$ ) (Fig. 6C,D). There was no detectable change in membrane input resistance after 4C3HPG or L-AP4 (Fig. 6C,D).

\section{Site of mGluR actions affecting inspiratory drive currents}

The reduction of the inspiratory drive current of PMNs caused by group-II and group-III mGluR agonists could result from actions either at presynaptic sites to decrease glutamate release or at postsynaptic sites to affect the responsiveness of ionotropic glutamate receptors to released glutamate. To investigate the underlying mechanism(s), we examined the effects of these agonists on the amplitude and frequency of mEPSCs. After treatment with TTX (1 $\mu \mathrm{M}$, bath), PMNs exhibit spontaneous mEPSCs (Fig. 7A) (Liu and Feldman, 1992; Dong and Feldman, 1995a). These events were collected from a 20-25 min control period (Fig. $7 B$, top) and subsequently 25-30 min during drug application (Fig. $7 B$, bottom). The time interval between successive mEPSCs and their peak amplitude were used to construct cumulative interval and amplitude histograms (see Fig. $7 C, D$ ).

The group-II agonist 4C3HPG caused a significant decrease in the frequency of mEPSCs (Fig. $7 C$ ). The decrease is indicated by the shift toward longer values of the interval histogram for 4C3HPG compared with the control histogram. In contrast, the amplitude of mEPSCs was not significantly altered by $4 \mathrm{C} 3 \mathrm{HPG}$, as indicated by overlapping cumulative amplitude histograms (Fig. 7D). The mean frequency of mEPSCs was $74 \pm 11 \%$ of control $(n=5)$ after 4C3HPG (30 $\mu \mathrm{M}$, bath) treatment (Fig. $7 E)$, whereas the mean amplitude of mEPSCs was not significantly altered $(97 \pm 9 \% ; n=5)$ by 4C3HPG (Fig. $7 E)$.

Similarly, the group-III agonist L-AP4 significantly decreased 

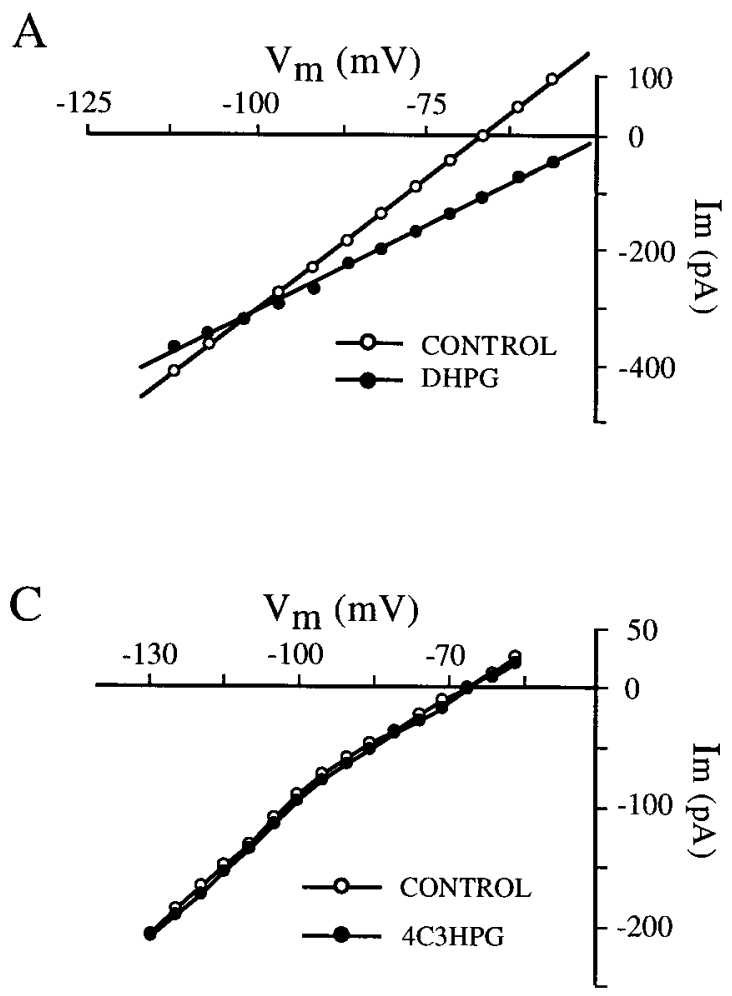

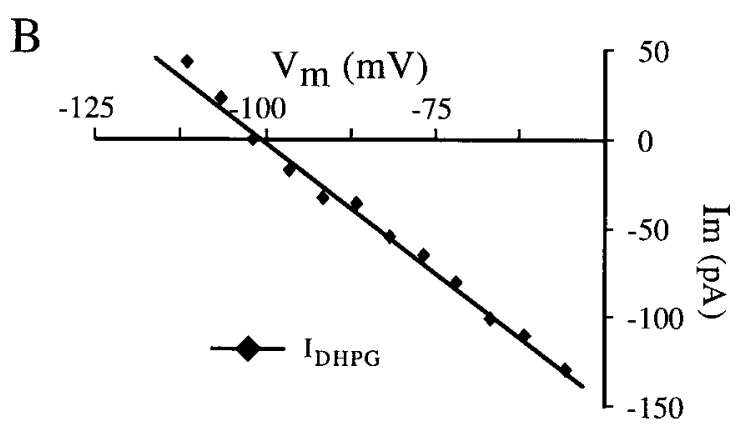

D

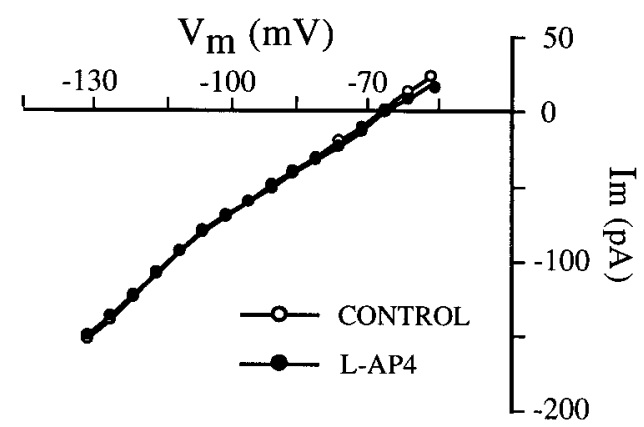

Figure 6. Differential effects of distinct mGluR subtypes on postsynaptic membrane properties. $A$, Membrane $I-V$ relationship before and after application of DHPG (30 $\mu \mathrm{M}$, bath). The $I-V$ curve was obtained by plotting current changes (averaged steady-state current values at 5-10 msec before offset of voltage step) against membrane potentials. Currents were generated by a series of command voltage pulses. Pulse step size was $5 \mathrm{mV}$; pulse width was $100 \mathrm{msec}$; and pulse frequency was $2 \mathrm{~Hz}$. Note that the membrane input resistance increased in the DHPG condition as indicated by the reduced slope of the $I-V$ plot. $B, I-V$ relationship, obtained by subtracting the $I-V$ relationship during DHPG treatment from that in the control condition, for the DHPG-induced inward current $\left(I_{\mathrm{DHPG}}\right)$. These experiments were performed in the presence of TTX $(1 \mu \mathrm{M}$, bath $)$. $C, D$, Membrane $I-V$ relationships before and after applications of 4C3HPG $(50 \mu \mathrm{M}$, bath; $C)$ and L-AP4 $(5 \mu \mathrm{M}$, bath; $D)$.

the frequency of mEPSCs while not affecting their amplitude. The mean frequency of mEPSCs after L-AP4 (5 $\mu \mathrm{M}$, bath) was reduced to $69 \pm 10 \%(n=4)$, whereas the mean amplitude was not significantly altered $(96 \pm 11 \% ; n=4$; Fig. $7 F)$.

\section{Endogenous activation of mGluRs shapes the inspiratory drive to PMNs}

To determine the endogenous activation of mGluRs and their physiological roles in synaptic transmission of inspiratory drive to PMNs, we examined the effects of their antagonists. The group-I mGluR antagonist AIDCA, applied locally over the PMN pool (2 $\mathrm{mM})$, significantly $(p<0.01)$ reduced the peak inspiratory drive current (Fig. $8 A, D)$ to $84 \pm 6 \%(n=5)$ of control. Concurrent with the decrease of PMN inspiratory drive currents, a reduction of $\mathrm{C} 4$ root activity by AIDCA occurred (data not shown). The effect of AIDCA began 25-30 sec after the onset of drug application and took 4-5 min to peak (Fig. $8 D$ ). After washout, inspiratory activity returned to the control level within 10-15 min.

In contrast, antagonists for group-II and group-III mGluRs enhanced the inspiratory activity of PMNs. EGLU, an antagonist for group-II mGluRs, increased inspiratory current in PMNs (Fig. $8 B, E$ ) and in C4 root activity (data not shown). Locally applied EGLU (2 mM) increased inspiratory current by $31 \pm 7 \%$ $(n=5)$ above control. The time course of the effect was similar to that of AIDCA (Fig. 8E). An antagonist for group-III, MSOP, also increased inspiratory drive current of PMNs (data not shown) and their output as C4 root activity (Fig. 8C).

\section{DISCUSSION}

This study demonstrates that inspiratory-modulated release of glutamate can activate various subtypes of mGluRs to affect differentially the excitability of PMNs. Using specific agonists, we identified mGluR subtypes mediating different effects. We propose that group-I mGluRs mediate the increase of excitability and that group-II and group-III mGluRs are responsible for the decrease of synaptic transmission.

\section{Postsynaptic group-I mGluRs mediate an increase in PMN excitability}

Activation of group-I mGluRs results in an increase in PMN excitability characterized by enhanced firing in response to inspiratory drive input. We found that the associated cellular responses, such as the production of an inward current and the increase in input resistance, persisted when synaptic transmission was blocked; these responses were not associated with any change in synaptic current. In addition, these effects were induced only by the agonist for group-I mGluRs and not by the agonists for the other groups. Taken together, our data suggest that postsynaptic group-I mGluRs mediate the increase of PMN excitability.

High levels of mGluR1 and mGluR5 mRNA expression are present in rat spinal cord (Valerio et al., 1997). Although there is a lack of information regarding the cellular localization of mGluRs in the phrenic nucleus, in many other brain areas group-I mGluRs are mainly localized postsynaptically (Martin et al., 1992; Baude et al., 1993; Lujan et al., 1996; Shigemoto et al., 
A

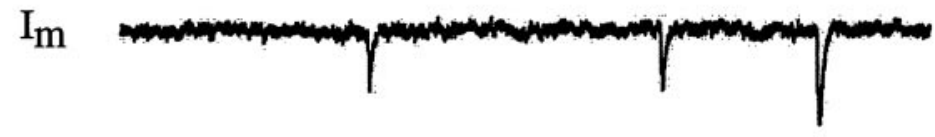
$20 \mathrm{pA}$

$200 \mathrm{~ms}$

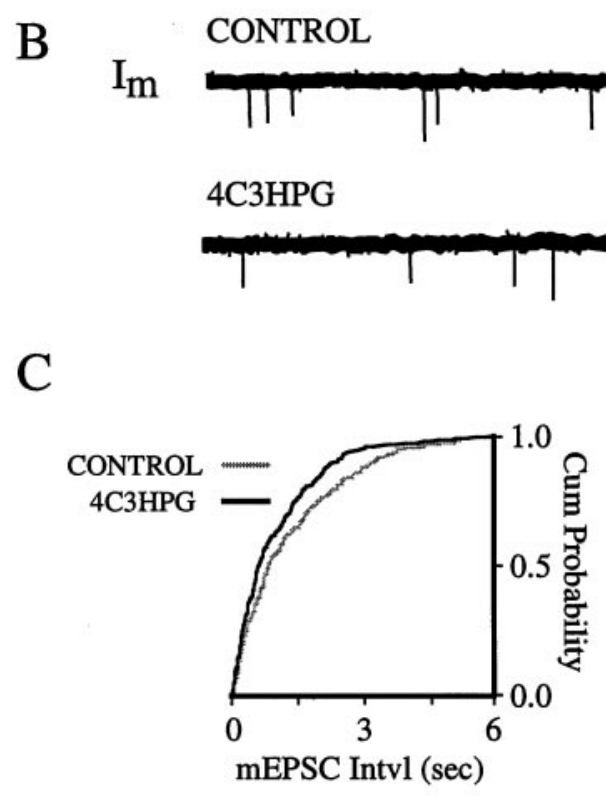

Figure 7. Effect of group-II and group-III agonists on mEPSCs in PMNs. A, Raw trace with higher temporal resolution showing typical mEPSCs after bath application of TTX $(1 \mu \mathrm{M}) . B$, Top, Raw trace showing mEPSCs before drug treatment. Bottom, Decrease of mEPSC frequency after 4C3HPG (30 $\mu \mathrm{M}$, bath) treatment. $C$, Cumulative (Cum) interval (Intvl) histograms of mEPSCs from the cell represented in $B$ before (1012 events; gray curve) and after (810 events; black curve) bath application of $4 \mathrm{C} 3 \mathrm{HPG}$, which induced a significant $(p<0.01)$ rightward shift in the cumulative distribution of mEPSC intervals (i.e., a decrease in mean EPSC frequency). $D$, Cumulative amplitude (Amp) histograms of mEPSCs from the same data sets shown in $C$. Note that there was no significant $(p>0.05)$ difference in the amplitude distributions between control and 4C3HPG conditions. Statistical significance for the difference between distributions was assessed by the Kolmogorov-Smirnov test. $E, F$, Summary of 4C3HPG $(E)$ and L-AP4 $(F)$ effects on the amplitude (Amp) and frequency (Freq) of mEPSCs. Each value (mean \pm SEM) was obtained by averaging the percentage changes of mean amplitude or interval (as the reciprocal of frequency) from cells tested with 4C3HPG (30 $\mu \mathrm{M}$, bath; $n=5)$ or L-AP4 $(5 \mu \mathrm{M}$, bath; $n=4)$. An asterisk indicates a significant difference $(p<0.05$; $t$ test) from control values.

$\mathrm{E}$

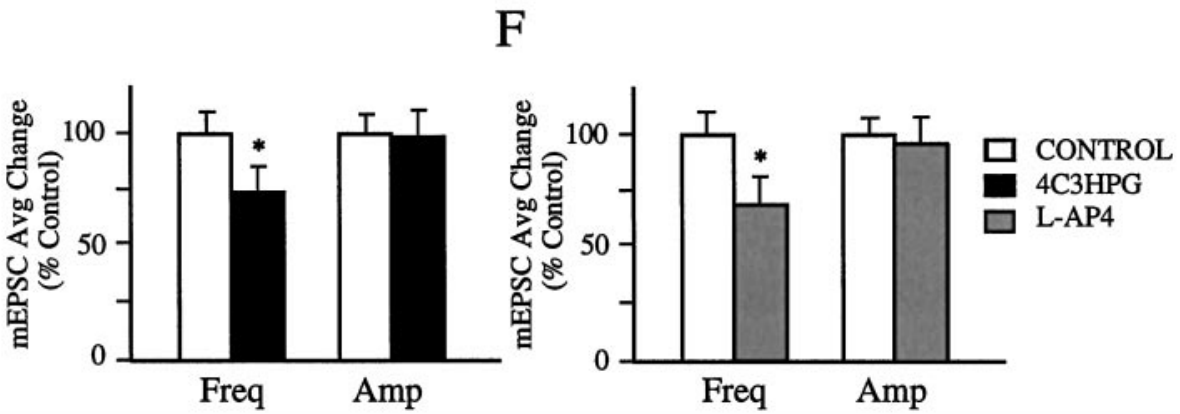

1997), where they increase neuronal excitability (Davies et al., 1995; Batchelor et al., 1997; Schoppa and Westbrook, 1997; Schrader and Tasker, 1997) consistent with our conclusion that postsynaptic group-I mGluRs increase PMN excitability. Our finding is in agreement with studies in other brain regions. Activation of postsynaptic group-I mGluRs increases firing of hypothalamic neurons (Schrader and Tasker, 1997) and induces a depolarization or an inward current and an associated increase in input resistance in hippocampal CA1 pyramidal neurons (Davies et al., 1995) and olfactory bulb mitral cells (Schoppa and Westbrook, 1997).

The effect of DHPG on PMNs resembles that elicited by $1 S, 3 R$-ACPD (Dong et al., 1996), including the production of an inward current that reverses at a potential close to the estimated $E_{\mathrm{K}}{ }^{+}(-95 \mathrm{mV})$ and an associated decrease in membrane conductance. Elevation of extracellular $\left[\mathrm{K}^{+}\right]$shifts the reversal potential of the $1 S, 3 R$-ACPD-induced inward current $\left(I_{\mathrm{ACPD}}\right)$ in the same direction as the $E_{\mathrm{K}}{ }^{+}$change. In addition, the $\mathrm{K}^{+}$channel blocker $\mathrm{Ba}^{2+}$ occludes the effects of $1 S, 3 R$-ACPD. We concluded that $I_{\mathrm{ACPD}}$ results principally from the blockade of a $\mathrm{Ba}^{2+}$-sensitive $\mathrm{K}^{+}$conductance (Dong et al., 1996). This mechanism may also underlie DHPG effects because the action of $1 S, 3 R$-ACPD and
DHPG on the postsynaptic membrane of PMNs is very likely mediated by the same mGluR group, i.e., group-I, according to the following evidence. (1) The effects produced by $1 S, 3 R$-ACPD and DHPG on the postsynaptic membrane of PMNs are quite similar, suggesting that the same signal transduction mechanisms are involved. (2) DHPG is highly selective for group-I over group-II and group-III mGluRs. (3) Although $1 S, 3 R$-ACPD can interact with group-II and/or group-III mGluRs, their agonists did not affect postsynaptic membrane properties of PMNs. We conclude that the postsynaptic component of $1 S, 3 R$-ACPD actions described previously was mediated via group-I mGluRs. Therefore, we suggest that blockage of a $\mathrm{Ba}^{+}$-sensitive $\mathrm{K}^{+}$conductance mediates the increase in PMN excitability by group-I mGluRs. In addition, changes in some other conductance(s) may be also involved in group-I mGluR-mediated action [see Dong et al. (1996), their Discussion].

\section{Presynaptic group-II and group-III mGluRs mediate a decrease of synaptic current}

Activation of group-II or group-III mGluRs decreased inspiratory drive current in PMNs. This effect was not observed when the agonist for group-I mGluRs was applied. To confirm further 

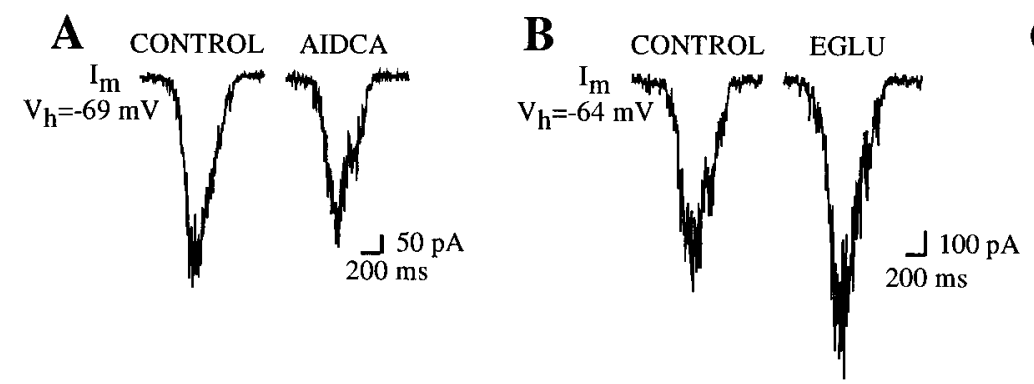

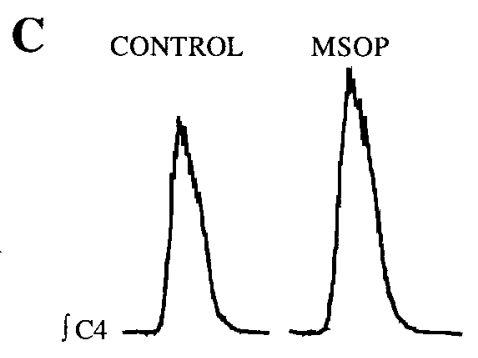

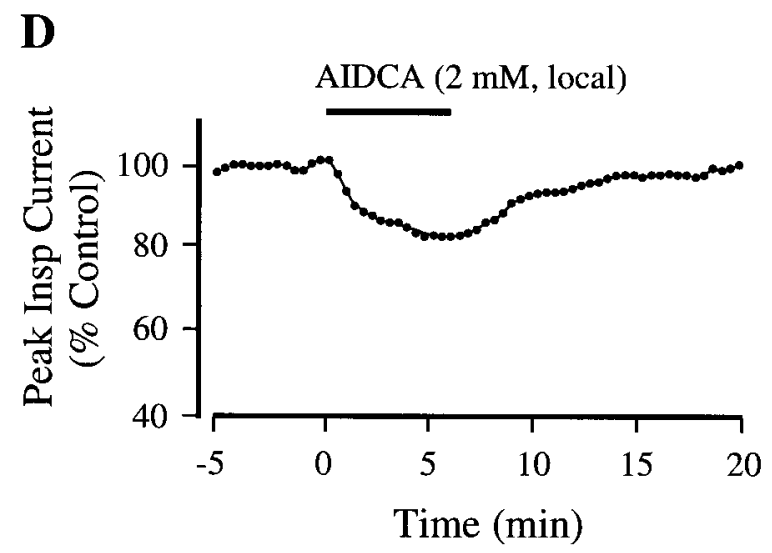

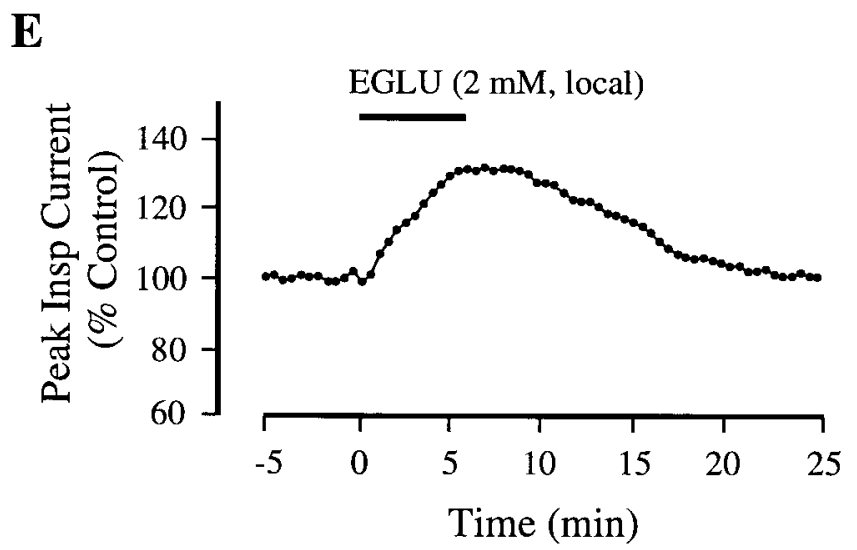

Figure 8. Endogenous activation of mGluRs during the inspiratory phase revealed by antagonists for different subgroups of mGluRs. $A$, Attenuation of inspiratory drive current of a PMN by the group-I mGluR antagonist AIDCA ( $2 \mathrm{~mm}$, local). $B$, Enhancement of inspiratory drive current of a PMN by the group-II mGluR antagonist EGLU $(2 \mathrm{~mm}$, local). $C$, Increase of inspiratory activity in C4 ventral roots by the group-III antagonist MSOP ( 2 mM, local). Traces are the averages of six consecutive inspiratory drive currents $\left(I_{m} ; A, B\right)$ or six integrated inspiratory discharges in $C 4$ roots $\left(\int C 4 ; C\right)$ before and after drug application. $D, E$, Time courses of changes of inspiratory currents in response to locally applied AIDCA $(D)$ and EGLU $(E)$. Each data point is the average of three consecutive peak inspiratory currents expressed as the percentage of the control value.

the involvement of group-II or group-III mGluRs, their second messenger pathways were examined. Group-II and group-III mGluRs are linked to cAMP (Tanabe et al., 1992, 1993; Nakajima et al., 1993; Okamoto et al., 1994; Saugstad et al., 1994; Duvoisin et al., 1995), whereas group-I mGluRs are coupled to phospholipase C (Masu et al., 1991; Abe et al., 1992; Aramori and Nakanishi, 1992). Elevation of intracellular cAMP concentration would mask or occlude an effect mediated via cAMP cascades. Pretreatment with the membrane-permeable cAMP analog 8-BrcAMP occluded the reduction of inspiratory drive by agonists for group-II and group-III, confirming that group-II and group-III mGluRs mediate the decrease of synaptic transmission of inspiratory drive.

The reduction of inspiratory drive current appears to result from a decrease of transmitter release because of activation of mGluR autoreceptors located at presynaptic terminals of bulbospinal inspiratory neurons onto PMNs. First, our mEPSC analysis showed that the frequency of mEPSCs was significantly reduced by both group-II and group-III agonists, whereas the mEPSC amplitude was unaffected. Because mEPSC frequency is dependent on transmitter release probability (Fatt and Katz, 1952; Redman, 1990), we assume that its reduction is a presynaptic action of a group-II or group-III agonist to decrease transmitter release from bulbospinal terminals onto PMNs. On the other hand, changes in mEPSC amplitude could result from a postsynaptic action of test drugs to affect the postsynaptic sensitivity to the endogenously released transmitter (Fatt and Katz, 1952; Redman, 1990; Kullmann and Siegelbaum, 1995). The fact that mEPSC amplitude was unaffected by either group-II or group-III agonists suggests a lack of their postsynaptic action. Although the origin of these mEPSCs was not identified, it is likely that the presynaptic terminals producing the mEPSCs include those of bulbospinal inspiratory neurons. Therefore, we extend our conclusion drawn from the mEPSCs to unitary EPSCs comprising the endogenous excitatory inspiratory drive current. However, caution must be taken when extrapolating the conclusions from mEPSC analysis of PMNs to inspiratory drive current. One important difference between spontaneous mEPSCs and evoked synaptic currents is that mEPSCs do not require $\mathrm{Ca}^{2+}$ influx (Scanziani et al., 1992; Scholz and Miller, 1992), which must be considered because activation of presynaptic mGluRs has been postulated to reduce $\mathrm{Ca}^{2+}$ influx (Stefani et al., 1994; Glaum and Miller, 1995; Yoshino and Kamiya, 1995). The reduction in mEPSC frequency we observed indicates that a $\mathrm{Ca}^{2+}$ independent mechanism, such as interference with the secretion cascade (Hayashi et al., 1993; Gereau and Conn, 1995; Scanziani et al., 1995; Tyler and Lovinger, 1995; Schoppa and Westbrook, 1997), is involved. Such a mechanism could also attribute, if not exclusively, to the inhibition of evoked transmitter release. Regardless of the precise mechanism, the decrease in transmitter release from bulbospinal presynaptic terminals by presynaptic group-II and group-III mGluRs leads to the reduction of inspiratory drive current.

Second, no alterations in steady-state membrane current or the input resistance of PMNs were produced by the agonist for group-II or group-III mGluRs, indicating that the decrease of 
inspiratory drive current by activation of these receptors is not caused by the shunting of postsynaptic currents.

Third, the decrease in synaptic current is most likely caused by direct action of drugs on the synapses of bulbospinal inspiratory terminals to PMNs rather than by an action on putative spinal interneurons relaying the descending inspiratory drive to PMNs. Bulbospinal transmission of inspiratory drive to PMNs seems to be mediated primarily by a monosynaptic pathway (Ellenberger and Feldman, 1988; Berger et al., 1989; Ellenberger et al., 1990; Lipski et al., 1994) and not by spinal interneurons (Davies et al., 1985; Lipski and Duffin, 1986; Palisses et al., 1989; Bellingham and Lipski, 1990; Grelot et al., 1993) (X.-W. Dong and J. L. Feldman, unpublished observations). In addition, when PMNs were isolated by TTX, group-II or group-III mGluR agonist continued to affect the frequency of mEPSCs. Therefore, drug effects seem to be attributable to direct action on impinging presynaptic terminals.

In many brain regions, group-II and group-III mGluRs appear predominantly localized in presynaptic terminals (Shigemoto et al., 1995, 1996, 1997). The presynaptic distribution is consistent with their physiological roles in modulating synaptic transmission. These mGluRs can inhibit transmitter release in areas such as the hippocampus (Forsythe and Clements, 1990; Baskys and Malenka, 1991; Gereau and Conn, 1995; Schrader and Tasker, 1997), thalamus (Salt and Eaton, 1995), hypothalamus (Schrader and Tasker, 1997), olfactory bulb (Trombley and Westbrook, 1992; Schoppa and Westbrook, 1997), and trigeminal motor nucleus (Del Negro and Chandler, 1998). We conclude that this is also the case for bulbospinal transmission of inspiratory drive to PMNs.

\section{Endogenous activity and functional significance of mGluRs}

We observed significant changes in the inspiratory-modulated activity of PMNs by antagonists for each of three groups of mGluRs, suggesting endogenous activation of all groups. The reduction of inspiratory drive current by the mGluR1 antagonist AIDCA suggests that mGluR1s, in addition to various ionotropic receptors (Liu et al., 1990; Greer et al., 1991), are activated by endogenously released glutamate during the inspiratory phase and the resultant current contributes to the total inspiratory drive current. The mGluR1-mediated inward current will produce an incremental increase in the inspiratory-modulated depolarization. The concurrent increase in membrane resistance should also increase this depolarization. Our finding that the EPSCs of PMNs are mediated by glutamate acting at both ionotropic and group-I mGluRs is consistent with observations in other brain areas. In hippocampal CA3 pyramidal cells, when the fast ionotropic response is blocked pharmacologically, stimulation of mossy fibers produces a depolarizing postsynaptic potential associated with a decrease in membrane conductance (Charpak and Gähwiler, 1991; Gerber et al., 1993). This EPSP is greatly reduced by a mGluR antagonist methyl-4-carboxyphenylglycine (Gerber et al., 1993). mGluR1s also mediate responses of thalamic neurons to noxious thermal somatosensory stimuli (Salt and Turner, 1998) and EPSPs at parallel fiber-Purkinje cell synapses in the cerebellum (Batchelor et al., 1997).

The enhancement of inspiratory drive current or discharges of PMNs by antagonists for group-II and group-III mGluRs is presumably caused by the blockade of presynaptic receptors. This finding suggests that, at least in this in vitro preparation, bulbospinal transmission is attenuated by endogenous activation of pre- synaptic group-II and group-III mGluRs. Such a presynaptic action may provide a rapid negative (autoregulatory) feedback to reduce further glutamate release under physiological conditions.

In summary, three groups of mGluRs are all functionally expressed in the synapses of bulbospinal inspiratory neuron terminals to PMNs. These receptors are activated during endogenous inspiratory drive transmission to modulate this process. Along with other modulatory systems, such as 5-HT (Lindsay and Feldman, 1993) and adenosine (Dong and Feldman, 1995a), different groups of mGluRs function to ensure that the synaptic transmission of inspiratory drive to spinal respiratory motoneurons is well adjusted to produce the appropriate respiratory motor output under widely varying physiological conditions with different ventilatory demands.

\section{REFERENCES}

Abe T, Sugihara H, Nawa H, Shigemoto R, Mizuno N, Nakanishi S (1992) Molecular characterization of a novel metabotropic glutamate receptor mGluR 5 coupled to inositol phosphate/Ca2 + signal transduction. J Biol Chem 267:13361-13368.

Aramori I, Nakanishi S (1992) Signal transduction and pharmacological characteristics of a metabotropic glutamate receptor, mGluR1, in transfected CHO cells. Neuron 8:757-765.

Barkat M (1991) Signal detection and estimation. Boston: Artech.

Baskys A, Malenka RC (1991) Agonists at metabotropic glutamate receptors presynaptically inhibit EPSCs in neonatal rat hippocampus. J Physiol (Lond) 444:687-701.

Batchelor AM, Knöpfel T, Gasparini F, Garthwaite J (1997) Pharmacological characterization of synaptic transmission through mGluRs in rat cerebellar slices. Neuropharmacology 36:401-403.

Baude A, Nusser Z, Roberts JDB, Mulvihill E, Mcilhinney RAJ, Somogyi $\mathrm{P}$ (1993) The metabotropic glutamate receptor (mGluR1 $\alpha$ ) is concentrated at perisynaptic membrane of neuronal subpopulations as detected by immunogold reaction. Neuron 11:771-787.

Bellingham MC, Lipski J (1990) Respiratory interneurons in the C5 segment of the spinal cord of the cat. Brain Res 533:141-146.

Berger AJ, Dick TE, Jodkowski JS, Viana F (1989) Phrenic motoneurons: descending inputs, electrical properties, and recruitment. In: Chemoreceptors and reflexes in breathing, cellular and molecular aspects (Lahiri S, Forster II RE, Davies R, Pack A, eds), pp 343-350.

Birse EF, Eaton SA, Jane DE, Jones PL, Porter RH, Pook PC, Sunter DC, Udvarhelyi PM, Wharton B, Roberts PJ (1993) Phenylglycine derivatives as new pharmacological tools for investigating the role of metabotropic glutamate receptors in the central nervous system. Neuroscience 52:481-488.

Bushell TJ, Jane DE, Tse HW, Watkins JC, Davies CH, Garthwaite J, Collingridge GL (1995) Antagonism of the synaptic depressant actions of L-AP4 in the lateral perforant path by MAP4. Neuropharmacology 34:239-241.

Charpak S, Gähwiler BH (1991) Glutamate mediates a slow synaptic response in hippocampal slice cultures. Proc R Soc Lond [Biol] 243:221-226.

Davies CH, Clarke VR, Jane DE, Collingridge GL (1995) Pharmacology of postsynaptic metabotropic glutamate receptors in rat hippocampal CA1 pyramidal neurones. Br J Pharmacol 116:1859-1869.

Davies JG, Kirkwood PA, Sears TA (1985) The distribution of monosynaptic connexions from inspiratory bulbospinal neurones to inspiratory motoneurones in the cat. J Physiol (Lond) 368:63-87.

Del Negro CA, Chandler SH (1998) Regulation of intrinsic and synaptic properties of neonatal rat trigeminal motoneurons by metabotropic glutamate receptors. J Neurosci 18:9216-9226.

Dong XW, Feldman JL (1995a) Modulation of inspiratory drive to phrenic motoneurons by presynaptic adenosine A1 receptors. J Neurosci 15:3458-3467.

Dong XW, Feldman JL (1995b) Differential modulation of synaptic transmission to phrenic motoneurons by metabotropic glutamate receptor subtypes. Soc Neurosci Abstr 21:765.

Dong XW, Feldman JL (1996) Role and mechanism of endogenously activated mGluR1 in modulating synaptic transmission to phrenic motoneurons. Soc Neurosci Abstr 22:598.

Dong XW, Morin D, Feldman JL (1996) Multiple actions of $1 S, 3 R$ - 
ACPD in modulating endogenous synaptic transmission to spinal respiratory motoneurons. J Neurosci 16:4971-4982.

Duvoisin RM, Zhang C, Ramonell K (1995) A novel metabotropic glutamate receptor expressed in the retina and olfactory bulb. J Neurosci 15:3075-3083.

Ellenberger HH, Feldman JL (1988) Monosynaptic transmission of respiratory drive to phrenic motoneurons from brainstem bulbospinal neurons in rats. J Comp Neurol 269:47-57.

Ellenberger HH, Feldman JL, Goshgarian HG (1990) Ventral respiratory group projections to phrenic motoneurons: electron microscopic evidence for monosynaptic connections. J Comp Neurol 302:707-714.

Fatt P, Katz B (1952) Spontaneous subthreshold activity at motor nerve endings. J Physiol (Lond) 117:109-128.

Feldman JL, Smith JC (1994) Neural control of respiratory pattern in mammals: an overview. In: Lung biology in health and disease: regulation of breathing (Dempsey J, Pack A, eds), pp 39-69. New York: Dekker.

Forsythe ID, Clements JD (1990) Presynaptic glutamate receptors depress excitatory monosynaptic transmission between mouse hippocampal neurones. J Physiol (Lond) 429:1-16.

Gallagher JP, Zheng F, Shinnick-Gallhager P (1994) Long-lasting modulation of synaptic transmission by metabotropic glutamate receptors. In: The metabotropic glutamate receptors, pp 173-193. Totowa, NJ: Humana.

Gerber U, Lüthi A, Gähwiler BH (1993) Inhibition of a slow synaptic response by a metabotropic glutamate receptor antagonist in hippocampal CA3 pyramidal cells. Proc R Soc Lond [Biol] 254:169-172.

Gereau IV RW, Conn PJ (1995) Multiple presynaptic metabotropic glutamate receptors modulate excitatory and inhibitory synaptic transmission in hippocampal area CA1. J Neurosci 15:6879-6889.

Glaum SR, Miller RJ (1995) Presynaptic metabotropic glutamate receptors modulate omega-conotoxin-GVIA-insensitive calcium channels in the rat medulla. Neuropharmacology 34:953-964.

Greer JJ, Smith JC, Feldman JL (1991) Role of excitatory amino acids in the generation and transmission of respiratory drive in neonatal rat. J Physiol (Lond) 437:727-749.

Grelot L, Milano S, Portillo F, Miller AD (1993) Respiratory interneurons of the lower cervical $(\mathrm{C} 4-\mathrm{C} 5)$ cord: membrane potential changes during fictive coughing, vomiting, and swallowing in the decerebrate cat. Pflügers Arch 425:313-320.

Hayashi Y, Momiyama A, Takahashi T, Ohishi H, Ogawa-Meguro R, Shigemoto R, Mizuno N, Nakanishi S (1993) Role of a metabotropic glutamate receptor in synaptic modulation in the accessory olfactory bulb. Nature 366:687-690.

Kingston AE, Burnett JP, Mayne NG, Lodge D (1995) Pharmacological analysis of 4-carboxyphenylglycine derivatives: comparison of effects on mGluR1 alpha and mGluR5a subtypes. Neuropharmacology 34:887-894.

Kullmann DM, Siegelbaum SA (1995) The site of expression of NMDA receptor-dependent LTP: new fuel for an old fire. Neuron 15:997-1002.

Libri V, Constanti A, Zibetti M, Postlethwaite M (1997) Metabotropic glutamate receptor subtypes mediating slow inward tail current (IADP) induction and inhibition of synaptic transmission in olfactory cortical neurones. Br J Pharmacol 120:1083-1095.

Lindsay AD, Feldman JL (1993) Modulation of respiratory activity of neonatal rat phrenic motoneurones by serotonin. J Physiol (Lond) 461:213-233.

Lindsay AD, Greer JJ, Feldman JL (1991) Phrenic motoneuron morphology in the neonatal rat. J Comp Neurol 308:69-79.

Lipski J, Duffin J (1986) An electrophysiological investigation of propriospinal inspiratory neurons in the upper cervical cord of the cat. Exp Brain Res 61:625-637.

Lipski J, Zhang X, Kruszewska B, Kanjhan R (1994) Morphological study of long axonal projections of ventral medullary inspiratory neurons in the rat. Brain Res 640:171-184.

Liu G, Feldman JL (1992) Quantal synaptic transmission in phrenic motor nucleus. J Neurophysiol 68:1468-1471.

Liu G, Feldman JL, Smith JC (1990) Excitatory amino acid-mediated transmission of inspiratory drive to phrenic motoneurons. J Neurophysiol 64:423-436.

Lujan R, Nusser Z, Roberts JD, Shigemoto R, Somogyi P (1996) Perisynaptic location of metabotropic glutamate receptors mGluR1 and mGluR5 on dendrites and dendritic spines in the rat hippocampus. Eur J Neurosci 8:1488-1500.

Macek TA, Winder DG, Gereau IV RW, Ladd CO, Conn PJ (1996)
Differential involvement of group II and group III mGluRs as autoreceptors at lateral and medial perforant path synapses. J Neurophysiol 76:3798-3806.

Martin LJ, Blackstone CD, Huganir RL, Price DL (1992) Cellular localization of a metabotropic glutamate receptor in rat brain. Neuron 9:259-270.

Masu M, Tanabe Y, Tsuchida K, Shigemoto R, Nakanishi S (1991) Sequence and expression of a metabotropic glutamate receptor. Nature 349:760-765

McCrimmon DR, Smith JC, Feldman JL (1989) Involvement of excitatory amino acids in neurotransmission of inspiratory drive to spinal respiratory motoneurons. J Neurosci 9:1910-1921.

Nakajima Y, Iwakabe H, Akazawa C, Nawa H, Shigemoto R, Mizuno N, Nakanishi S (1993) Molecular characterization of a novel retinal metabotropic glutamate receptor mGluR6 with a high agonist selectivity for L-2-amino-4-phosphonobutyrate. J Biol Chem 268:11868-11873.

Netzeband JG, Parsons KL, Sweeney DD, Gruol DL (1997) Metabotropic glutamate receptor agonists alter neuronal excitability and $\mathrm{Ca} 2+$ levels via the phospholipase $\mathrm{C}$ transduction pathway in cultured Purkinje neurons. J Neurophysiol 78:63-75.

Okamoto N, Hori S, Akazawa C, Hayashi Y, Shigemoto R, Mizuno N, Nakanishi S (1994) Molecular characterization of a new metabotropic glutamate receptor mGluR7 coupled to inhibitory cyclic AMP signal transduction. J Biol Chem 269:1231-1236.

Palisses R, Persegol L, Viala D (1989) Evidence for respiratory interneurones in the $\mathrm{C} 3-\mathrm{C} 5$ cervical spinal cord in the decorticate rabbit. Exp Brain Res 78:624-632.

Pin JP, Bockaert J (1995) Get receptive to metabotropic glutamate receptors. Curr Opin Neurobiol 5:342-349.

Pin JP, Duvoisin R (1995) The metabotropic glutamate receptors: structure and functions. Neuropharmacology 34:1-26.

Poncer JC, Shinozaki H, Miles R (1995) Dual modulation of synaptic inhibition by distinct metabotropic glutamate receptors in the rat hippocampus. J Physiol (Lond) 485:121-134.

Press WH, Flannery BP, Teukolsky SA, Vetterling WT (1989) Numerical recipes: the art of scientific computing. Cambridge, United Kingdom: Cambridge.

Redman S (1990) Quantal analysis of synaptic potentials in neurons of the central nervous system. Physiol Rev 70:165-198.

Salt TE, Eaton SA (1995) Distinct presynaptic metabotropic receptors for L-AP4 and CCG1 on GABAergic terminals: pharmacological evidence using novel alpha-methyl derivative mGluR antagonists, MAP4 and MCCG, in the rat thalamus in vivo. Neuroscience 65:5-13.

Salt TE, Turner JP (1998) Reduction of sensory and metabotropic glutamate receptor responses in the thalamus by the novel metabotropic glutamate receptor-1-selective antagonist $S$-2-methyl-4-carboxyphenylglycine. Neuroscience 85:655-658.

Saugstad JA, Kinzie JM, Mulvihill ER, Segerson TP, Westbrook GL (1994) Cloning and expression of a new member of the L-2-amino-4phosphonobutyric acid-sensitive class of metabotropic glutamate receptors. Mol Pharmacol 45:367-372.

Scanziani M, Capogna M, Gahwiler BH, Thompson SM (1992) Presynaptic inhibition of miniature excitatory synaptic currents by baclofen and adenosine in the hippocampus. Neuron 9:919-927.

Scanziani M, Gähwiler BH, Thompson SM (1995) Presynaptic inhibition of excitatory synaptic transmission by muscarinic and metabotropic glutamate receptor activation in the hippocampus: are $\mathrm{Ca} 2+$ channels involved? Neuropharmacology 34:1549-1557.

Schoepp DD, Conn PJ (1993) Metabotropic glutamate receptors in brain function and pathology. Trends Pharmacol Sci 14:13-20.

Schoepp DD, Goldsworthy J, Johnson BG, Salhoff CR, Baker SR (1994) 3,5-Dihydroxyphenylglycine is a highly selective agonist for phosphoinositide-linked metabotropic glutamate receptors in the rat hippocampus. J Neurochem 63:769-772.

Scholz KP, Miller RJ (1992) Inhibition of quantal transmitter release in the absence of calcium influx by a $G$ protein-linked adenosine receptor at hippocampal synapses. Neuron 8:1139-1150.

Schoppa NE, Westbrook GL (1997) Modulation of mEPSCs in olfactory bulb mitral cells by metabotropic glutamate receptors. J Neurophysiol 78:1468-1475.

Schrader LA, Tasker JG (1997) Presynaptic modulation by metabotropic glutamate receptors of excitatory and inhibitory synaptic inputs to hypothalamic magnocellular neurons. J Neurophysiol 77:527-536.

Shigemoto R, Wada E, Ohishi H, Takada M, Mizuno M, Roberts JDB, Somogyi P (1995) Differential presynaptic localization of metabo- 
tropic glutamate receptor subtypes, mGluR2/3 and mGluR7 in the rat hippocampus. Soc Neurosci Abstr 21:338.

Shigemoto R, Kulik A, Roberts JDB, Ohishi H, Nusser Z, Kaneko T, Somogyi P (1996) Target-cell-specific concentration of a metabotropic glutamate receptor in the presynaptic active zone. Nature 381:523-525.

Shigemoto R, Kinoshita A, Wada E, Nomura S, Ohishi H, Takada M, Flor PJ, Neki A, Abe T, Nakanishi S, Mizuno N (1997) Differential presynaptic localization of metabotropic glutamate receptor subtypes in the rat hippocampus. J Neurosci 17:7503-7522.

Smith JC, Feldman JL (1987) In vitro brainstem-spinal cord preparations for study of motor systems for mammalian respiration and locomotion. J Neurosci Methods 21:321-333.

Smith JC, Liu G, Feldman JL (1988) Intracellular recording from phrenic motoneurons receiving respiratory drive in vitro. Neurosci Lett 88:27-32.

Stefani A, Pisani A, Mercuri NB, Bernardi G, Calabresi P (1994) Activation of metabotropic glutamate receptors inhibits calcium currents and GABA-mediated synaptic potentials in striatal neurons. J Neurosci 14:6734-6743.

Tanabe Y, Masu M, Ishii T, Shigemoto R, Nakanishi S (1992) A family of metabotropic glutamate receptors. Neuron 8:169-179.

Tanabe Y, Nomura A, Masu M, Shigemoto R, Mizuno N, Nakanishi S (1993) Signal transduction, pharmacological properties, and expression patterns of two rat metabotropic glutamate receptors, mGluR3 and mGluR4. J Neurosci 13:1372-1378.

Thomas NK, Jane DE, Tse HW, Watkins JC (1996) alpha-Methyl de- rivatives of serine-O-phosphate as novel, selective competitive metabotropic glutamate receptor antagonists. Neuropharmacology 35:637-642.

Tones MA, Bendali N, Flor PJ, Knöpfel T, Kuhn R (1995) The agonist selectivity of a class III metabotropic glutamate receptor, human mGluR4a, is determined by the N-terminal extracellular domain. NeuroReport 7:117-120.

Trombley PQ, Westbrook GL (1992) L-AP4 inhibits calcium currents and synaptic transmission via a G-protein-coupled glutamate receptor. J Neurosci 12:2043-2050.

Tyler EC, Lovinger DM (1995) Metabotropic glutamate receptor modulation of synaptic transmission in corticostriatal co-cultures: role of calcium influx. Neuropharmacology 34:939-952.

Valerio A, Paterlini M, Boifava M, Memo M, Spano P (1997) Metabotropic glutamate receptor mRNA expression in rat spinal cord. NeuroReport 8:2695-2699.

Van der Kloot W (1991) The regulation of quantal size. Prog Neurobiol 36:93-130.

Vignes M, Clarke VR, Davies CH, Chambers A, Jane DE, Watkins JC, Collingridge GL (1995) Pharmacological evidence for an involvement of group II and group III mGluRs in the presynaptic regulation of excitatory synaptic responses in the CA1 region of rat hippocampal slices. Neuropharmacology 34:973-982.

Yoshino M, Kamiya H (1995) Suppression of presynaptic calcium influx by metabotropic glutamate receptor agonists in neonatal rat hippocampus. Brain Res 695:179-185. 